\title{
Difference in shear-wave velocities of silt and silty clay obtained \\ using various methods
}

\author{
Fang $\mathrm{Yi}^{1, \mathrm{a}}$, Li Shuang ${ }^{2, \mathrm{~b}}$ \\ ${ }^{1}$ Institute of Crustal Dynamics, CEA, Beijing 100085, China; \\ ${ }^{2}$ CCCC Highway Consultants CO., Ltd., Beijing 10088, China; \\ afyyyfyyy@vip.qq.com, blishuang_1st@163.com
}

\begin{abstract}
The shear-wave velocity of rock and soil masses is the quantitative basis for understanding the dynamic parameters of site soil and evaluating its dynamic performance. The field test and laboratory test are two major methods and it is necessary to study the difference of the test results obtained by the two methods, especially for conventional soils like silt and silty clay. This study selected two typical sites to conduct field test and laboratory tests of shear-wave velocity and measured the shear-wave velocities of the obtained undisturbed soil samples of silt and silty clay in the laboratory. The results suggest that: (1) almost all shear-wave velocities of silt and silty clay obtained in laboratory test were faster than those in field test; (2) the main reason causing the difference between the two methods was that soil samples lost water during the acquisition and transportation, resulting in declining soil moisture; and (3) factors including structural change of soil samples, existence of soft and hard interlayers, and testing environmental in the field also contributed to the difference of the test results of shear-wave velocity.
\end{abstract}

Keywords: Testing of shear-wave velocities, Silty clay, Difference, Water content

\section{Introduction}

Shear-wave velocity, an important parameter to reflect dynamic property of soils, provide a basis for calculating relative parameters of rock bodies, assessing sand liquefaction and dividing types of engineering sites ${ }^{[1]}$. At present, there are mainly two methods to test shear-wave velocity: field test and laboratory test. The former, using single-hole method, is the most popular way due to its high operability and low cost while significantly affected by field environment ${ }^{[2,3]}$. Despite circumventing the disadvantages of field method, laboratory test is affected by disturbed soil samples. Obviously, the two methods both have strengths and weaknesses and can support each other sometimes, yet leaving confusing relationship.

Nowadays researchers in China have carried out research on their relationship. Zhang Li et.al ${ }^{[4]}$ studied the difference of the test results of shear-wave velocity acquired using ground excitation method and laboratory test, verifying the direct relationship of the buried depth of soil layers and clay content with respect to the difference. This research, however, explored their relationship in the view of different deposition states of soils without fully considering actual situation of sample disturbance and soil layers. On this basis, two typical sites in Tangshan, Hebei province, China, were adopted in this study to conduct field test for shear-wave velocity by excitation in holes at first. Next, laboratory test 
were conducted for the shear-wave velocity of the acquired undisturbed soil samples of silt and silty clay using an improved dynamic triaxial apparatus. Finally, the reason causing difference was discussed and analyzed.

\section{Engineering and geological situation of typical fields}

The two typical sites selected for the study were both in Tangshan, located in alluvial-proluvial plain formed by Luan River where river landform is developed and riverway evolves frequently, leaving behind a great number of paleochannels. Previous exploration achievements demonstrate that the surface of the region of the typical sites is covered by Quaternary system and generated by the alleviation of Dou River. With respect to the lithology, cohesive soils and sandy soils are deposited alternately, showing an obvious sedimentary rhythm. Cobbles are scattered in local areas while pebbles can be found in the bottom of strata in part of the sites.

Typical site 1 is located in Nanhu District of Tangshan, and drilling works showed that the overburden thickness is around $120 \mathrm{~m}$. Its lithology is mainly characterized by the alternate deposition of silty clay and sands with thin silt interlayers. As to typical site 2, it is in the downtown of Tangshan and drilling works revealed that the overburden thickness is about $50 \mathrm{~m}$, with alternate deposition of silty clay and sands in terms of the lithology. The completely weathered mudstone can be found at the depth of $53 \mathrm{~m}$.

Besides, thin-wall sampling method was adopted to obtain 10 and 7 undisturbed soil samples of $20 \mathrm{~cm}$ in the height with $10 \mathrm{~cm}$ in the diameter at two typical sites, respectively, comprising silty clay and silt.

\section{Test methods for shear-wave velocity}

\section{Field test}

The field shear-wave velocity test in this study employed hole excitation of single-hole method, and the test devices was OYO suspended wave-velocity logger made in Japan, which greatly improved the accuracy of determining the first breaks of $S$ wave through wavelet analysis ${ }^{[5]}$. The test devices are demonstrated as Figure 1.

The test method is as follows: firstly, the three-component geophone was put into the hole and subjected to zero-point adjustment; afterwards, the geophone was moved downwards to the bottom of the hole and excited the seismic source every dropping $10 \mathrm{~m}$ to ensure that the apparatus ran well. At last, the seismic source was excited every $1 \mathrm{~m}$ after touching the bottom, so as to detect the shear-wave velocity from the bottom to the top.

The velocity of shear waves passing through the holes per meter can be calculated by formula $\mathbf{V s}=\Delta H / \triangle T$ where $\triangle H$ represents the distance between two geophones (m), valuing $1 \mathrm{~m}$ in the research and $\triangle \mathrm{T}$ means the time difference of a shear wave arriving the two geophones, (ms). 


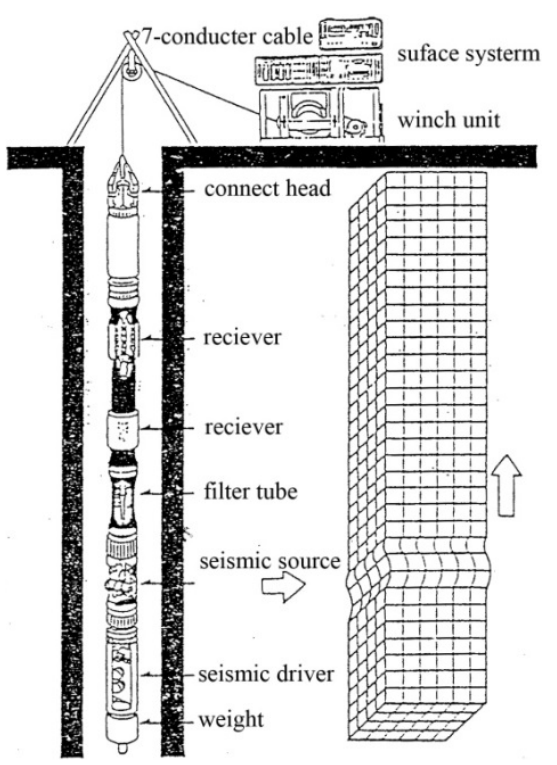

Fig1.P-S wave logging ${ }^{[5]}$

\section{Laboratory test}

The testing device of shear-wave velocity in the laboratory in this study was the dynamic triaxial apparatus equipped with a HX-100 electric servos control, and the shear-wave sensor was put between the upper and lower pressure caps. The test device consisted of a triaxial pressure chamber, transmitting and receiving sensors for shear waves and a DB4 ultrasonic velocity measuring apparatus, as shown in Figure 2. Its principle is to determine the shear-wave velocity of samples according to axial length and time for shear waves passing through.

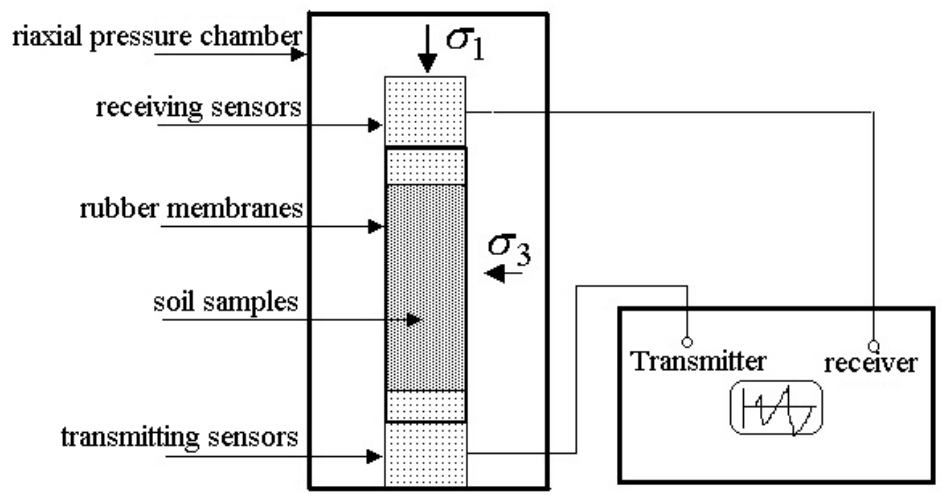

Fig2.Measurement device of shear wave velocity ${ }^{[6]}$

The testing method was as follows: firstly, being covered with rubber membranes, the prepared undisturbed soil samples (3.91 cm in the diameter and $8.0 \mathrm{~cm}$ in the height) were placed in the triaxial pressure chamber. Then isotropic consolidation pressure determined in the light of effective overburden pressure of corresponding soil layers of the soil samples was applied on the soil samples to squeeze water out until they were consolidated. Finally, shear-wave velocity was calculated according to time taken by shear waves to pass through soil samples and the height of consolidated soil samples ${ }^{[6]}$.

The shear-wave velocity test device is widely used in ocean engineering. It is worth noting that the samples were saturated before testing and isotropic consolidation pressure was exerted to soil samples for drainage and consolidation.

Formula Vs=L/t is used to calculate the velocity of shear waves passing through soil 
samples where $\mathrm{L}$ and $\mathrm{t}$ refer to the final height of the soil samples and the time for shear wave travelling through the soil samples $(\mu \mathrm{s})$, respectively.

\section{Test results}

The test results of the two methods for shear-wave velocity are shown in Tables 1 and 2 as well as Figures 3 and 4 . It is necessary to point out here that the height of the soil samples in laboratory test was only $8 \mathrm{~cm}$. For the convenience of comparison below, general works take it as the shear-wave velocity in this layer. So the depth of laboratory test results in Table 1 was in accordance with that in fieldtest. Besides, the authors measured the soil moisture under natural state and that in laboratory test for further analysis.

Tabel1. The Field and Laboratory Test values of Shear Wave Velocity and contrast on the water content of natural soil and soil samples Consolidation (the first typical site)

\begin{tabular}{cccccccc}
\hline $\begin{array}{c}\text { Soil } \\
\text { samples } \\
\text { number }\end{array}$ & $\begin{array}{c}\text { Test } \\
\text { depth } \\
(\mathrm{m})\end{array}$ & Lithology & $\begin{array}{c}\text { Field } \\
\text { test } \\
\text { result } \\
(\mathrm{m} / \mathrm{s})\end{array}$ & $\begin{array}{c}\text { Laboratory } \\
\text { test (m/s) }\end{array}$ & $\begin{array}{c}\text { Relative } \\
\text { error of } \\
\text { shear-wave } \\
\text { velocity }\end{array}$ & $\begin{array}{c}\text { Soil } \\
\text { moisture } \\
\text { of } \\
\text { natural } \\
\text { soils (\%) }\end{array}$ & $\begin{array}{c}\text { Soil moisture } \\
\text { after } \\
\text { consolidation } \\
(\%)\end{array}$ \\
\hline 1 & 28 & silt & 360 & 388 & $7 \%$ & 17.5 & 15.6 \\
2 & 34 & silt & 372 & 427 & $13 \%$ & 17.5 & 15.8 \\
3 & 36 & silt & 343 & 362 & $5 \%$ & 18.1 & 17.7 \\
4 & 47 & silty clay & 351 & 319 & $-10 \%$ & 22.1 & 22.2 \\
5 & 49 & silty clay & 333 & 316 & $-5 \%$ & 23.1 & 23.6 \\
6 & 57 & silty clay & 362 & 439 & $18 \%$ & 23.4 & 15.1 \\
7 & 59 & silty clay & 336 & 387 & $13 \%$ & 23.4 & 17.8 \\
8 & 88 & silty clay & 420 & 470 & $11 \%$ & 22.7 & 18.4 \\
9 & 100 & silt & 433 & 519 & $17 \%$ & 16.8 & 16.7 \\
10 & 122 & silty clay & 467 & 529 & $13 \%$ & 20.2 & 15.6 \\
\hline
\end{tabular}

Tabel2. The Field and Laboratory Test values of Shear Wave Velocity and contrast on the water content of natural soil and soil samples Consolidation (the second typical site)

\begin{tabular}{cccccccc}
\hline $\begin{array}{c}\text { Soil } \\
\text { samples } \\
\text { number }\end{array}$ & $\begin{array}{c}\text { Test } \\
\text { depth } \\
(\mathrm{m})\end{array}$ & Lithology & $\begin{array}{c}\text { Field } \\
\text { test } \\
\text { result } \\
(\mathrm{m} / \mathrm{s})\end{array}$ & $\begin{array}{c}\text { Laboratory } \\
\text { test }(\mathrm{m} / \mathrm{s})\end{array}$ & $\begin{array}{c}\text { Relative } \\
\text { error of } \\
\text { shear-wave } \\
\text { velocity }\end{array}$ & $\begin{array}{c}\text { Soil } \\
\text { moisture } \\
\text { of natural } \\
\text { soils (\%) }\end{array}$ & $\begin{array}{c}\text { Soil moisture } \\
\text { after } \\
\text { consolidation } \\
(\%)\end{array}$ \\
\hline 1 & 12 & silt & 201 & 227 & $11 \%$ & 12 & 24.1 \\
2 & 15 & silty clay & 209 & 338 & $38 \%$ & 15 & 25.1 \\
3 & 24 & silty clay & 279 & 325 & $14 \%$ & 24 & 26.7 \\
4 & 33 & silty clay & 310 & 387 & $20 \%$ & 33 & 17.1 \\
5 & 42 & silt & 368 & 431 & $15 \%$ & 42 & 19.8 \\
6 & 48 & silty clay & 361 & 394 & $8 \%$ & 48 & 23.1 \\
7 & 51 & silty clay & 446 & 453 & $2 \%$ & 51 & 20.1 \\
\hline
\end{tabular}

From Figures 3 and 4 as well as Tables 1 and 2, it can be seen that:

(1) Most of the test results of field test were less than those of laboratory test, except for the depths of $47 \mathrm{~m}$ and $49 \mathrm{~m}$ in typical site 1 where the later was larger than the former.

(2) The maximum relative error of the two methods was $38 \%$, while the rest remained within $20 \%$, which verified that the test results of the two methods have high reliability.

(3) The change trend of results of field test was basically in accordance with that of laboratory test, accounting for the similar change trend of lithology in the two test results. 


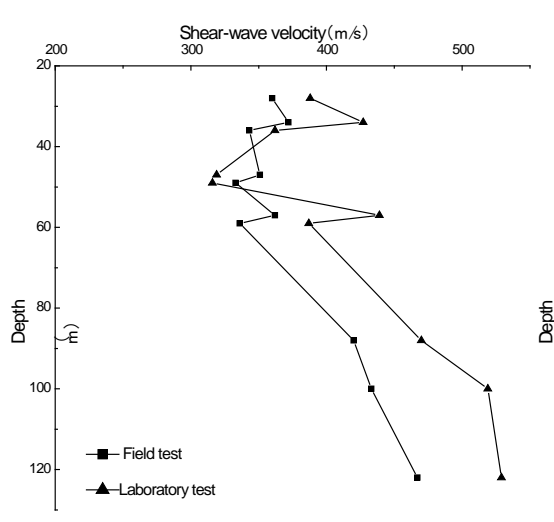

Fig.3 Comparison of shear wave velocity values between field and laboratory test for the first typical site

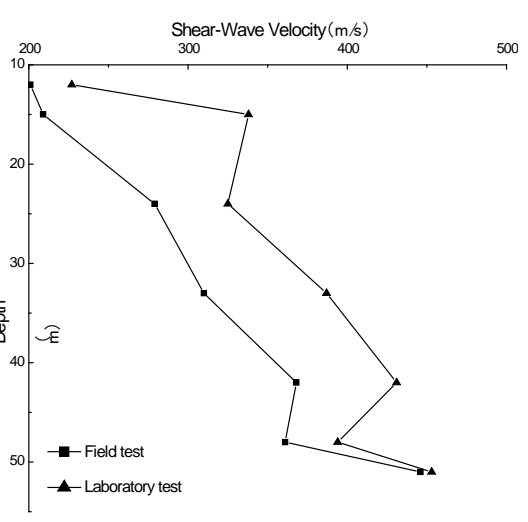

Fig.4 Comparison of shear wave velocity values between field and laboratory test for the second typical site

\section{Discussions}

Field shear-wave velocity test can reflect the natural state of soil layers while is significantly affected by human factors and field environment. In contrary, laboratory test is mainly limited by the disturbance of soil samples. Therefore, the reasons causing the difference of the results of field test and laboratory test were as follows:

(1) Change of soil moisture

Soil moisture reflects the compactness and density of soil samples to some extent. Existing studies indicate that the larger the soil moisture is, the smaller the tested shear-wave velocity of soil samples ${ }^{[7]}$. Water in soil samples is easily lost in the collection and transportation. Although the samples were statured and consolidated by drainage before laboratory test to restore soil moisture to the initial state, the difference of soil moisture still can be seen in the samples of field tests and consolidated soil samples in the table: almost all the soil moistures of the former were more than those of the later. However, it can be found that soil moistures in soil tests at the buried depths of $47 \mathrm{~m}$ and $49 \mathrm{~m}$ in typical site 1 were less than those of consolidated samples, in accordance with the difference of shear-wave velocity test results by the two methods at the buried depths. As a result, change of soil moisture is the main reason accounting for the difference of results between laboratory and fieldtests.

(2) Structural change of soil samples

The collection and transportation of soil samples can change not only the content of soil moisture, but also its structure. Although soils are cementation through long-time natural deposition, unavoidable disturbance in the process of collection and transportation can lead to loose soil samples. Before testing shear-wave velocity in laboratories, confining pressure is expected to be applied to soil samples in the light of the density and buried depths of soil samples to restore the soils in the natural state which is difficult to be exactly realized. So the exerted pressure leads to looser or more compacted soil samples compared with natural soils, resulting in a smaller or larger shear-wave velocity in the laboratory test compared with field test.

(2) Existence of soft and hard interlayers

Field test obtained the shear-wave velocity of 100 -cm-thick soils while the final height of soil samples in laboratory test was no more than $8 \mathrm{~cm}$, so it is inevitable that hard or soft interlayers existed in field layers, which accelerated or decelerated the normal wave velocity of 
this layer. The maximum relative error of results of fieldtest and laboratory test was $38 \%$ at the buried depth of $15 \mathrm{~m}$ in typical site 2 . It can be inferred that the location was exactly in hard interlayer, thereby leading to a higher value in laboratory test.

(3) Environmental factors in field test

Though field test can directly reflect the natural state of soils against disturbance of soil samples, it is easily affected by environment factors like ground motion, especially in shallow strata where even a slight shake can cause variation of waveforms. This kind of influence inevitability makes errors in the test results of shear-wave velocity, thereby inducing the difference of two methods.

\section{Summary}

This study compared the results of field and laboratory tests for shear-wave velocity in two typical sites in Tangshan, and the conclusions came into being as follows:

(1) Most results of field test were smaller than those of laboratory test except for those at two buried depths where the former was larger than the later. The maximum relative error of the two methods was 38\% with the rest remaining within $20 \%$, and the results obtained in the two tests showed consistent change trends with depth, which verified the reliability of the two methods.

(2) Soil moisture, structural change, existence of soft and hard interlayers, and field environment of field test led to the difference of results in field and laboratory test for shear-wave velocity.

\section{Acknowledgement}

In this paper, the research was sponsored by research grant from Institute of Crustal Dynamics, China Earthquake Administration (No. ZDJ2015-04).

\section{References}

[1]Chang Shibiao, Zhang Sumin. Manual of engineering geology (4th ed). Beijing:China Architecture and Building Press, 2006:278

[2] Guo Mingzhu, Jia Lianjun, Tie Rui et al. Analysis on Current Situation of Shear-velocity Measurement Method. Northwestern Seismological Journal,2011, Volume 33 supplement: 21-23

[3]Lu Zilin, Fu Haiqing, Hu Chao et al. Comparison of two methods of drilling shear wave velocity test. North China Earthquake Sciences,2014,33(2):45-49

[4] Zhang Li, Wang Jianhua, Cheng Guoyong. Study on Field and Laboratory Test of Shear Wave Velocity of Soil Specimen[J]. Site Investigation Science and Technology,2003,4:15-17

[5] Chen Xugeng, Tian Jiayong, Wang Enfu et al. Wave-velocity logging based on wavelet analysis. Journal of Earthquake Engineering and Engineering Vibration.2007, 27(1):163-159

[6]Wang Jianhua, Cheng Guoyong, Zhang Li. A New Device to Measure the Shear Wave Velocity of Soil Samples. Journal of Tianjin University(Science and Technology), 2004,37(2):152-156

[7]Li Qingshan. Effect of subgrade soil water content on shear wave velocity. Transpo World(Construction and maintenance machinery), 2010,13:120-122 